\title{
Slice Location Dependence of Aortic Regurgitation Measurements with MR Phase Velocity Mapping
}

\author{
George P. Chatzimavroudis
}

Cleveland State University

Peter G. Walker

University of Leeds

Follow this and additional works at: https://engagedscholarship.csuohio.edu/encbe_facpub

Irhn N. Oshinski

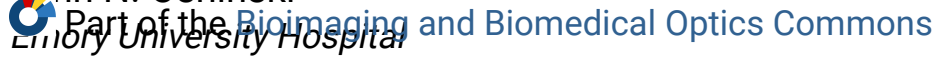

How does access to this work benefit you? Let us know!

Rober ishersanchtatement

Emory University Hospital

This is the accepted version of the following article: Chatzimavroudis GP, Walker PG, Oshinski

BuderimtPRttigPettigrew RI, Yoganathan AP. Slice location dependence of aortic regurgitation Emeary Uugikersity HAppithe phase velocity mapping. Magnetic Resonance in Medicine.

1997;37:545-551., which has been published in final form at http://onlinelibrary.wiley.com/doi/

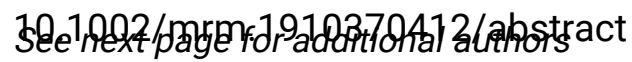

\section{Original Citation}

Chatzimavroudis GP, Walker PG, Oshinski JN, Franch RH, Pettigrew RI, Yoganathan AP. Slice location dependence of aortic regurgitation measurements with MR phase velocity mapping. Magnetic Resonance in Medicine. 1997;37:545-551.

\section{Repository Citation}

Chatzimavroudis, George P.; Walker, Peter G.; Oshinski, John N.; Franch, Robert H.; Pettigrew, Roderic I.; and Yoganathan, Ajit P., "Slice Location Dependence of Aortic Regurgitation Measurements with MR Phase Velocity Mapping" (1997). Chemical \& Biomedical Engineering Faculty Publications. 99.

https://engagedscholarship.csuohio.edu/encbe_facpub/99

This Article is brought to you for free and open access by the Chemical \& Biomedical Engineering Department at EngagedScholarship@CSU. It has been accepted for inclusion in Chemical \& Biomedical Engineering Faculty Publications by an authorized administrator of EngagedScholarship@CSU. For more information, please contact library.es@csuohio.edu. 


\section{Authors}

George P. Chatzimavroudis, Peter G. Walker, John N. Oshinski, Robert H. Franch, Roderic I. Pettigrew, and Ajit P. Yoganathan 


\title{
Slice Location Dependence of Aortic Regurgitation Measurements with MR Phase Velocity Mapping
}

\author{
George P. Chatzimavroudis, Peter G. Walker, John N. Oshinski, Robert H. Franch, \\ Roderic I. Pettigrew, Ajit P. Yoganathan
}

\begin{abstract}
Although several methods have been used clinically to assess aortic regurgitation (AR), there is no "gold standard" for regurgitant volume measurement. Magnetic resonance phase velocity mapping (PVM) can be used for noninvasive blood flow measurements. To evaluate the accuracy of PVM in quantifying AR with a single imaging slice in the ascending aorta, in vitro experiments were performed by using a compliant aortic model. Attention was focused on determining the slice location that provided the best results. The most accurate measurements were taken between the aortic valve annulus and the coronary ostia where the measured $(M$ and actual $(X)$ flow rate had close agreement $(Y=0.954 \times+0.126$, $r^{2}=0.995$, standard deviation of error $\left.=0.139 \mathrm{~L} / \mathrm{min}\right)$. Beyond the coronary ostia, coronary flow and aortic compliance negatively affected the accuracy of the measurements. In vivo measurements taken on patients with AR showed the same tendency with the in vitro results. In making decisions regarding patient treatment, diagnostic accuracy is very important. The results from this study suggest that higher accuracy is achieved by placing the slice between the aortic valve and the coronary ostia and that this is the region where attention should be focused for further clinical investigation.
\end{abstract}

Key words: aortic regurgitation; regurgitant volume; magnetic resonance phase velocity mapping; aortic compliance.

\section{INTRODUCTION}

Chronic aortic regurgitation (AR) leads to left ventricular dysfunction which, if untreated, can cause death. Knowledge of the severity of the disease is important, because it is used to guide patient management and to determine timing for valve replacement surgery.

Traditional methods, such as angiography (1), have been used to quantify $A R$, but they are invasive and semi-quantitative at best. A number of invasive and noninvasive echocardiographic techniques $(2-5)$ were investigated to assess $A R$, with only qualitative results. Color Doppler echocardiography and magnetic resonance im- aging (MRI) studies related the geometrical parameters of the regurgitant jet in the left ventricle (LV) with the severity of $A R(6-11)$, but the results correlated only fairly with angiographic grading data. Generally, technical limitations make these techniques unsatisfactory and, in addition, no direct value for the aortic regurgitant volume (ARV) can be determined. MRI volumetric studies (11-13) tried to measure the ARV as a difference between the left and right ventricular stroke volumes, but this approach is not valid in the simultaneous presence of regurgitation of other heart valves. Another clinical method, the proximal isovelocity surface area (PISA) method (14) is not applicable to the measurement of AR, because it is affected by the geometry of the valve (15) and the confinement by the walls of the aorta (16). Therefore, there is still a need for a reliable method to accurately quantify $A R$.

Magnetic resonance phase velocity mapping (PVM) is a technique capable of providing accurate blood velocity measurements (17-19). By positioning an imaging slice perpendicular to the long axis of a vessel, blood velocity through that slice can be measured over the entire crosssectional area of the vessel and then the instantaneous flow rate and the volume over any specified period of time can be calculated. PVM has been used to measure the ARV in vivo $(13,20-22)$ with promising results. However, each study involved different measurement protocols, with different slice locations and imaging parameters. One should note that, if the imaging slice is located in the ascending aorta superior to the sinotubular junction, the regurgitant flow includes the coronary flow. At the same time, because of aortic compliance, there will be a decrease of the aortic diameter during diastole forcing some blood to flow towards the valve, that will never pass through the slice, and the rest of blood to flow through the slice, but in the forward direction towards the systemic circulation. This will cause an underestimation of the regurgitant flow rate. A possible solution could be to place the slice in the vicinity of the aortic valve. There, however, the more complex flow environment could affect the accuracy of PVM measurements. The effects of these factors on the accuracy of the ARV measurements have not been investigated. Since there is no other reliable in vivo quantitative method for measuring AR, the accuracy of the PVM technique must be examined in an in vitro environment, using a model with a geometry similar to the anatomical, where the flow rates can be easily controlled and measured. Furthermore, the factors under investigation can be studied separately or in combination and much stronger conclusions regarding their effects can be drawn. 
The aim of this study was to investigate, in an in vitro environment, how accurate magnetic resonance phase velocity mapping is in quantifying the aortic regurgitant volume, and to study the effects of coronary flow, aortic compliance and velocity field on this accuracy. In addition, preliminary measurements in vivo were taken to better evaluate the in vitro results.

\section{METHODS}

\section{In Vitro Measurements}

A straight silicone model of the ascending aorta, with a stentless porcine aortic valve, the sinuses of Valsalva and two Tygon tubes (3 mm ID) representing the coronary arteries, were used for in vitro measurements (Fig. 1). Regurgitation was created by placing plastic cylindrical tubes between the leaflets of the valve to prevent complete closure. Water was used as the blood analog fluid in all experiments for simplicity, although its viscocity is approximately 3.5 times lower than that of blood, since, in the aortic root, flow is predominantly driven by inertia compared with viscous mechanisms. The model was mounted in a large water-filled container to provide a stronger MR signal.

To investigate the effect of coronary artery flow on the ARV measurements, the model was placed in a steady flow loop. The direction of the flow was similar to that of a regurgitant flow, i.e., from the aorta to the LV. The regurgitant flow rate was measured with a rotameter and the coronary flow rate by timing the filling of a graduated cylinder. The entire system was placed in a 1.5 Tesla scanner (ACS Gyroscan, Philips Medical Systems, Shelton, CT). Initially, a coronal scout spin-echo image was acquired [slice thickness (ST): $7 \mathrm{~mm}$; field of view (FOV): $300 \mathrm{~mm}$; echo time (TE): $25 \mathrm{~ms}$; repetition time (TR): 432 ms; matrix size: $256 \times 256$ ]. A number of transverse, gradient-echo, velocity-encoded images were taken at four locations: (i) at the valve annulus level; (ii) between the valve annulus and the coronary ostia $(0.5 \mathrm{~cm}$ from the

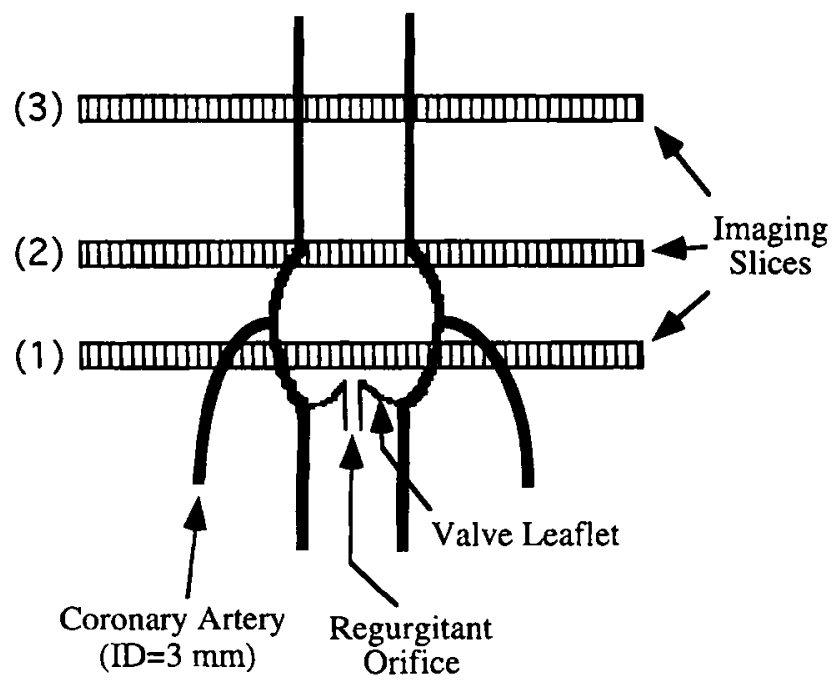

FIG. 1. Aortic root model. Three slice locations are shown: between the valve and the coronary ostia (1); at the sinotubular junction (2); and in the ascending aorta (3). valve) or at Location 1 in Fig. 1; (iii) at the sinotubular junction ( $2.0 \mathrm{~cm}$ from the valve) or at Location 2 in Fig. 1; and (iv) beyond the sinotubular junction $(4.0 \mathrm{~cm}$ from the valve) or at Location 3 in Fig. 1. A range of regurgitant orifice diameters $(1,3$, and $5 \mathrm{~mm})$ and orifice velocities $(2-5 \mathrm{~m} / \mathrm{s})$ were used to cover the clinical range of severity of AR. As a result, a range of regurgitant flow rates from 0.1 to $5.5 \mathrm{~L} / \mathrm{min}$ were used. A range of velocity encoding values $(25-500 \mathrm{~cm} / \mathrm{s})$ was used depending on slice location. The coronary artery flow rate was $0.3 \mathrm{~L} / \mathrm{min}$. For each acquisition (ST: $5 \mathrm{~mm}$; FOV: $200 \mathrm{~mm}$; TR: $30 \mathrm{~ms}$; $T E$ : $6-9 \mathrm{~ms}$; Flip angle: $35^{\circ}$; matrix size: $128 \times 128$; pixel size: $1.56 \times 1.56 \mathrm{~mm}$ ), a modulus and a phase image were acquired (Figs. 2a and $2 b$ ).

To investigate the effect of aortic compliance on the ARV measurements, pulsatile flow was generated by a computer-controlled piston pump (SuperPump, SPS 3891 Vivitro Systems Inc., Victoria, British Columbia, Canada) by using the same aortic model. No coronary flow was allowed to focus on the compliance effect. The aortic flow rate was measured with a brass transit time ultrasonic flow probe $(24 \mathrm{~N}$ in-line, Transonic Systems Inc., Ithaca, NY), located next to the valve in the LV side, by using a single channel flowmeter (T-108, Transonic Systems Inc.). The flow waveform was recorded on a Macintosh IIci computer by digitizing the analog signal from the flowmeter with an A/D board (NB-MIO-16, National Instruments Inc., Austin, TX) and using the LabVIEW software (Version 3.0, National Instruments, Inc.). After the coronal scout image was acquired by using ECG triggering, the velocity-encoded transverse images were taken at three locations: (i) $0.5 \mathrm{~cm}$ from the valve (corresponding to the region between the valve annulus and the coronary ostia), Location 1 ; (ii) $2.0 \mathrm{~cm}$ from the valve (sinotubular junction), Location 2; and (iii) $4.0 \mathrm{~cm}$ from the valve, Location 3. A range of degrees of severity of AR was produced (ARV $=7-75 \mathrm{ml} / \mathrm{beat}$ ) by using four regurgitant orifices $(2,3,4$, and $5 \mathrm{~mm}$ in diameter). The change in aortic diameter between systole and diastole in normal cases is $10-15 \%$ (23), but it can be outside of this range, depending on factors such as age or the pathological state (24) of the aortic wall. In these experiments, the diameter change was varied between $10 \%$ and $50 \%$ to obtain more complete results. The total output of the piston pump was $4.2 \mathrm{~L} / \mathrm{min}$ with a cycle rate of 60 beats/ min. Retrospective ECG gating was used to acquire 20 frames per cycle (same imaging parameters as in steady flow).

\section{In Vivo Measurements}

To evaluate the in vitro results clinically, measurements were taken on five normal volunteers and three patients with AR [moderate-to-severe (Grade 3) as assessed by angiography and echocardiography]. After the aortic root was located in the spin-echo scout image (Fig. 3a), an LVOT gradient-echo cine scout acquisition (TR: $30 \mathrm{~ms}$; TE: $6 \mathrm{~ms}$; FOV: $250 \mathrm{~mm}$; ST: $5 \mathrm{~mm}$ ) was taken to provide additional information about the valve and the coronary ostia (Fig. 3b). On these images, the valve was located from direct visualization of the valve leaflets or from a dark area (reduced signal) just proximal to the regurgitant 


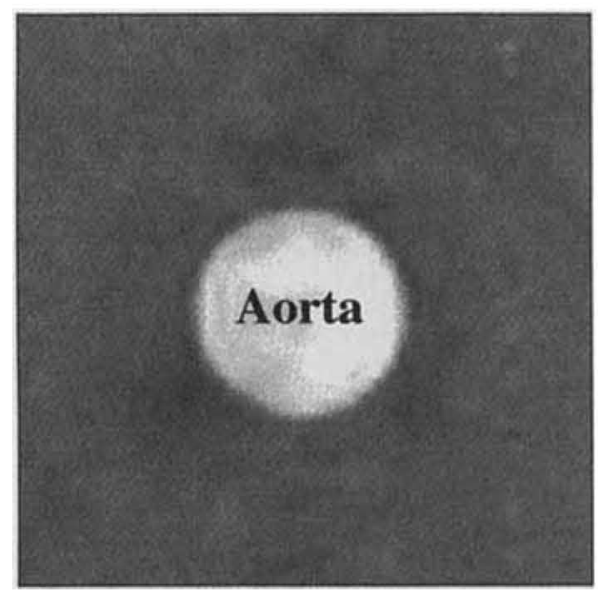

a

FIG. 2. (a) Modulus and (b) phase transverse gradient-echo images (FOV: $200 \mathrm{~mm}$; ST: $5 \mathrm{~mm}$; TR: $30 \mathrm{~ms}$; TE: $8 \mathrm{~ms}$; matrix size: $128 \times 128$; retrospective ECG cardiac gating; 20 phases; 2 signals averaged).

orifice caused by flow acceleration. Also, the origins of the coronary arteries were seen by combining the scouts and were used as a guide for the location of the slice between the valve annulus and the coronary ostia. Similar to the in vitro protocol, measurements were taken perpendicular to the long axis of the aorta in three locations (Fig. 3a): (i) between the valve annulus and the coronary ostia; (ii) at the sinotubular junction; and (iii) 2 $\mathrm{cm}$ beyond the sinotubular junction. The velocity encoding value used was varied $(50-200 \mathrm{~cm} / \mathrm{s})$ depending on slice location. Each velocity-encoded acquisition required approximately $4 \mathrm{~min}$, depending on the heart rate of the volunteer.

\section{Image And Data Analysis}

The phase images were initially processed to remove the phase offset due to eddy currents. Pixels of stationary tissue should have phase values corresponding to zero velocity. Based on that, an "error image" was created for each phase image. In this "error image," each pixel represented the phase offset value for the corresponding pixel in the initial phase image ("errors" for all pixels were determined through $2 \mathrm{D}$ regression analysis using, as data, the phase offset values from the stationary tissue pixels). Thus, a set of "error images" was created and, by subtracting each of them from the corresponding initial phase image, pixel by pixel, a new corrected phase image was created (25). The cross-section of the aorta was identified and selected on each modulus image of the cycle separately (based on the higher signal intensity of flowing blood in the aorta) and the selection was applied to the phase images. The phase was converted to velocity, based on the linearity between MR signal phase and velocity, and integration of this velocity over the crosssectional area of the aorta yielded the flow rate. Then, the ARV was calculated by integrating the instantaneous regurgitant flow rate curve over diastole. Also, from the modulus images, the change in the cross-sectional area of the aorta was observed throughout the cardiac cycle. By knowing the aortic cross-sectional area change at the slice Locations 1, 2, and 3 (Fig. 1), the volume change between these locations was determined. These direct measured volume changes were compared with the change in the regurgitant volume measured with PVM at the same locations to investigate more quantitatively the effect of compliance.

\section{Statistical Analysis}

A sign test was applied to determine if there was a significant difference in the regurgitant flow rates between measurements at different locations. The sign test was used because the number of data in each case was small for application of the $t$ test. Flowrates were normalized with respect to the actual regurgitant flow rates. Interobserver variability was studied by separate analysis of the images by two investigators who were blinded to one another's analysis. Regression analysis and a sign test were applied to determine the degree of the reproducibility.

\section{RESULTS}

\section{In Vitro}

Figure 4 shows the measured regurgitant flow rates between the valve and the coronary ostia (Location 1). The measured flow rate excluded the coronary flow, thus giving the actual regurgitant flow rate. This is seen from the data points that tend to fall on the solid line representing the regurgitant flow rate and from the regression line where the slope is essentially 1.0 and the intercept is small. However, when the slice was placed at the sinotubular junction (Location 2), the measured flow rate included the coronary flow. This was observed from the data points falling on the dashed line representing the combined (regurgitant plus coronary) flow rate and from the regression equation $\left[y=0.995 x+0.338, r^{2}=0.995\right.$, standard deviation of error $(\mathrm{SDE})=0.152 \mathrm{~L} / \mathrm{min}]$, where the slope was essentially 1.0 and the intercept was approximately $0.3 \mathrm{~L} / \mathrm{min}$ (coronary flow rate). Similar results were observed for measurements taken beyond the sinotubular junction (location 3: $y=0.984 x+0.286, r^{2}=$ $0.998, \mathrm{SDE}=0.077 \mathrm{~L} / \mathrm{min}$ ). A sign test showed that there was a significant difference when the measurements between the valve annulus and the coronary ostia were compared with those at the sinotubular junction or beyond it $(P<0.05)$. No significant difference was found between the measured flow rates at Location 1 and the actual regurgitant flow rates $(P=0.18)$. There was no significant difference between the measurements at slice Locations 2 and $3(P=0.18)$ which, in addition, were significantly different to the actual regurgitant flow rate $(P<0.005)$. PVM measurements at the valve annulus 

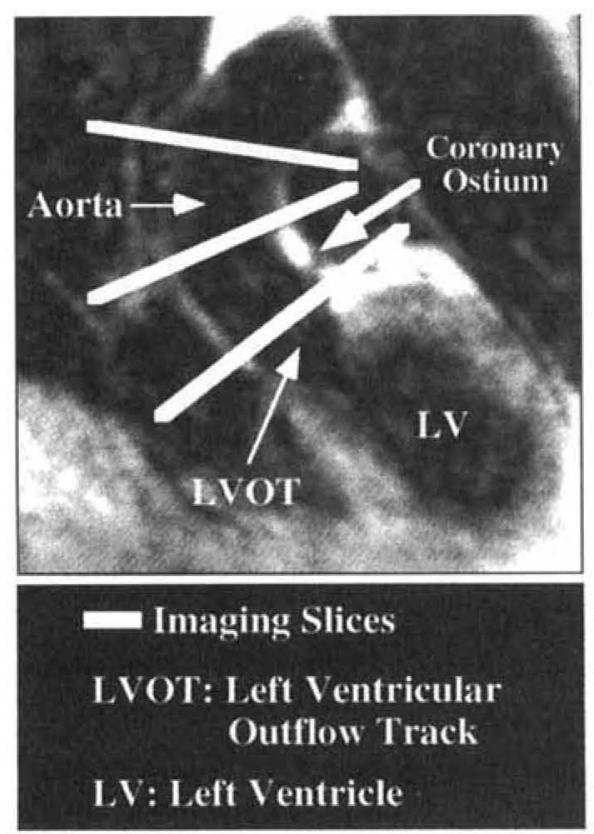

a

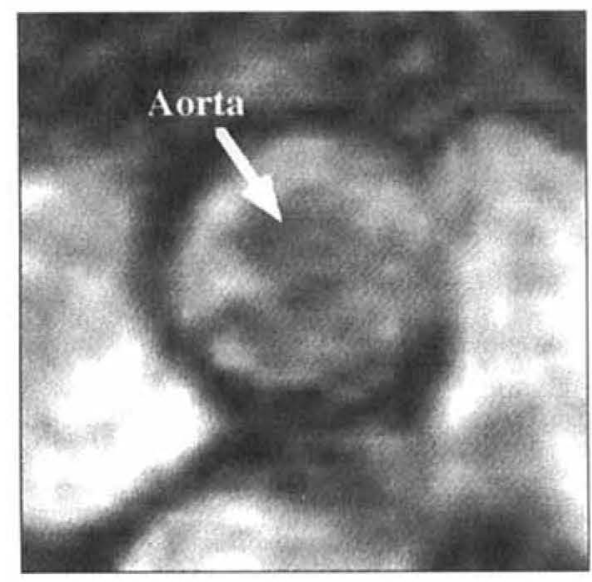

c
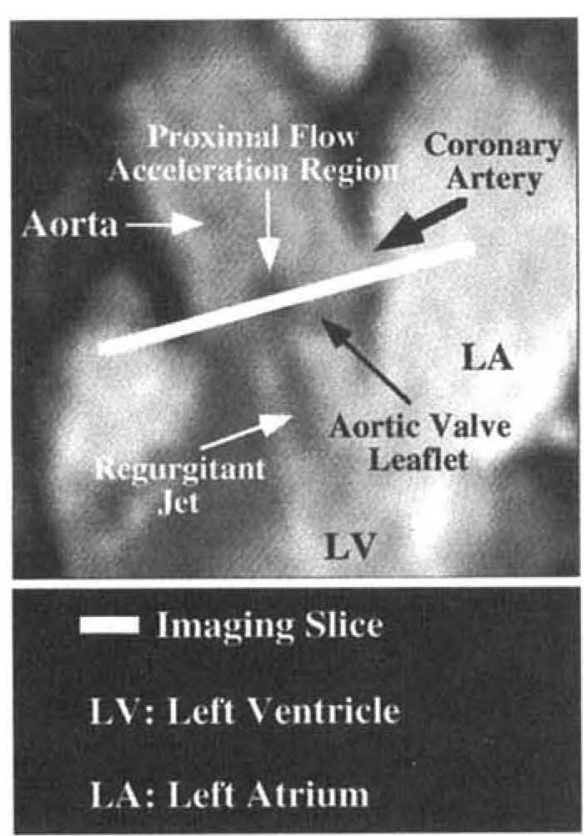

b

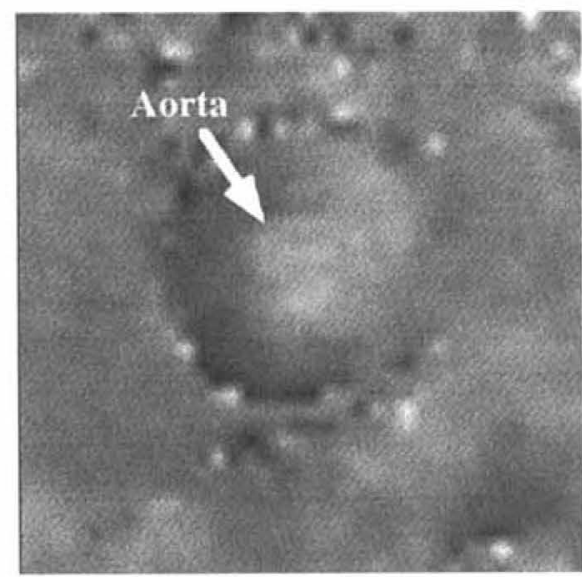

d

valve annulus increased. Hence, for slice Location 2, this error was approximately $12 \%$ and for slice Location 3 , it was approximately $22 \%$. As seen in Fig. 6, the aortic volume change during the cardiac cycle between slice Locations 1 and 2 or between Locations 2 and 3 , as measured directly from the modulus images, was well related to the difference in the measured ARV between those specific locations $(y=$ $\left.1.1079 x-0.0661, r^{2}=0.87\right)$.

\section{In Vivo}

No significant ARV was measured in any of the healthy volunteers $(<2 \mathrm{ml} / \mathrm{beat})$. In the case of the patients, there was a decrease in the measured $\mathrm{ARV}$ as the slice was moved away from the valve in the ascending aorta (Fig. 7).

The interobserver variability of the regurgitant volume calculations was found to be very small by simple regression analysis on the calculated ARVs $\left(y=1.050 x-0.441, r^{2}\right.$ $=0.998, \mathrm{SDE}=0.782 \mathrm{ml}, P<$ 0.001 , where $y$ : Reviewer 1 and $x$ : Reviewer 2). Also, a sign test showed that there was no significant difference between the results of the two separate analyses $(P=\mathbf{0 . 1 1})$.

\section{DISCUSSION}

ostian-echo coronal scout image and slice locations: between the valve and the coronary TR: $432 \mathrm{~ms}$; TE: $25 \mathrm{~ms} ; 2$ signals averaged). The aortic root and coronary ostium are seen. (b) LVOT gradient-echo image to locate the valve and coronary ostia (FOV: $250 \mathrm{~mm}$; ST: $5 \mathrm{~mm}$; TR: $30 \mathrm{~ms}$; TE: $6 \mathrm{~ms}$; flip angle: $30^{\circ} ; 2$ signals averaged). (c) modulus and (d) phase images acquired in the aortic root (FOV: $200 \mathrm{~mm}$; ST: $5 \mathrm{~mm}$; TR: $30 \mathrm{~ms}$; TE: $6 \mathrm{~ms}$; flip angle: $35^{\circ}$; retrospective gating; 2 signals averaged). The aorta is clearly distinguished.

level were not accurate $\left(y=0.455 x+0.191, r^{2}=0.31\right.$, $\mathrm{SDE}=1.361 \mathrm{~L} / \mathrm{min}$ ).

Figure 5 shows the change in the measured ARV as the distance between the slice and the valve annulus increases, in the case of 35,40 , and $45 \mathrm{ml} /$ beat actual ARV (moderate-to-severe). At $0.5 \mathrm{~cm}$ from the valve, the measurements were very accurate. However, there was a decrease in the measured ARVs as the distance of the slice from the valve increased. This behavior was observed for the entire set of ARVs used in the experiments. The average error in the measurements (based on the actual ARV) at slice Location 1 was approximately $2 \%$. This error increased as the distance of the slice from the
Although recent studies have shown that the single slice PVM technique has great potential for quantifying AR, determining the proper measurement location is of great importance in the clinical establishment of the technique. This depends, first of all, on understanding the effects of fluid mechanics factors on the PVM results.

When the slice was placed above the coronary ostia, the measurement of the regurgitant flow included the coronary flow, resulting in an overestimation of the severity of regurgitation. However, coronary flow is generally small (2-4 $\mathrm{ml} /$ beat) and its effect on the measurement of the regurgitant volume is, therefore, small in cases of moderate and severe AR. For example, if the actual regurgitant volume is $30 \mathrm{ml} / \mathrm{beat}$, the measured regurgitant volume at the sinotubular junction, could be $34 \mathrm{ml} /$ beat considering a coronary flow of $4 \mathrm{ml} /$ beat, 


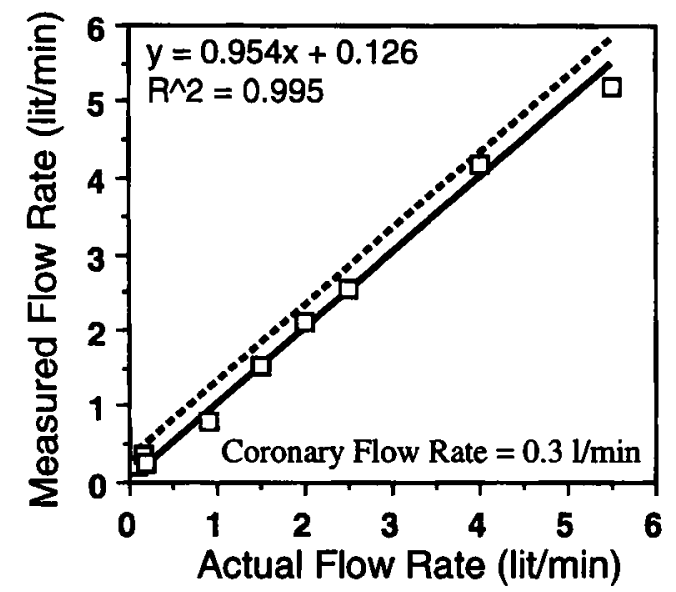

$\begin{array}{lll}Y & Y=X & \text { (Regurgitant Flow) } \\ -- & Y=X+0.3 & \text { (Regurgitant + Coronary Flow) } \\ \square & \begin{array}{l}\text { Measurements }\end{array}\end{array}$

FIG. 4. Steady flow results. Imaging slice located $0.5 \mathrm{~cm}$ from valve annulus (between coronary ostia and valve).

leading to a relatively small error of $13 \%$. This will not be the case in milder AR cases. For an actual regurgitant volume of $10 \mathrm{ml} / \mathrm{beat}$, the measured regurgitant volume at the sinotubular junction, could be as high as $14 \mathrm{ml} /$ beat, leading to a $40 \%$ error.

The observed decrease in the measured ARV as the slice location was moved cranially away from the aortic valve shows the effect of aortic compliance. Measurements taken between the valve annulus and the coronary ostia were accurate whereas the errors in the measured ARV increased with the distance of the slice from the valve ( $>20 \%$ ). To obtain a more quantitative sense of the compliance effect, the change in the measured ARV between two different slice locations was compared with the aortic volume change, in diastole, between the same

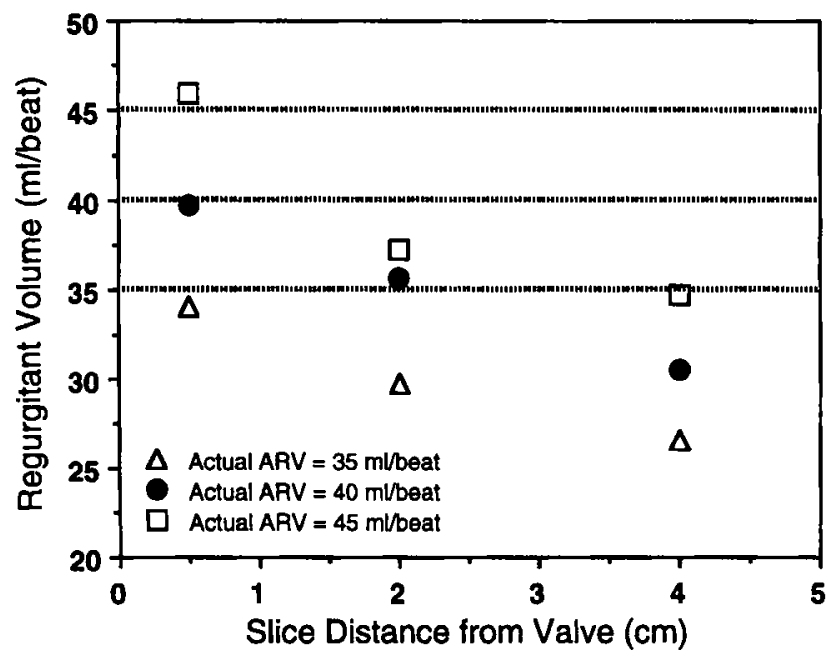

FIG. 5. Pulsatile flow results. Measured regurgitant volume at $\mathbf{0 . 5}$, 2 , and $4 \mathrm{~cm}$ from the valve annulus for three different aortic regurgitant volumes: 35,40 , and $45 \mathrm{ml} /$ beat (moderate-to-severe AR).

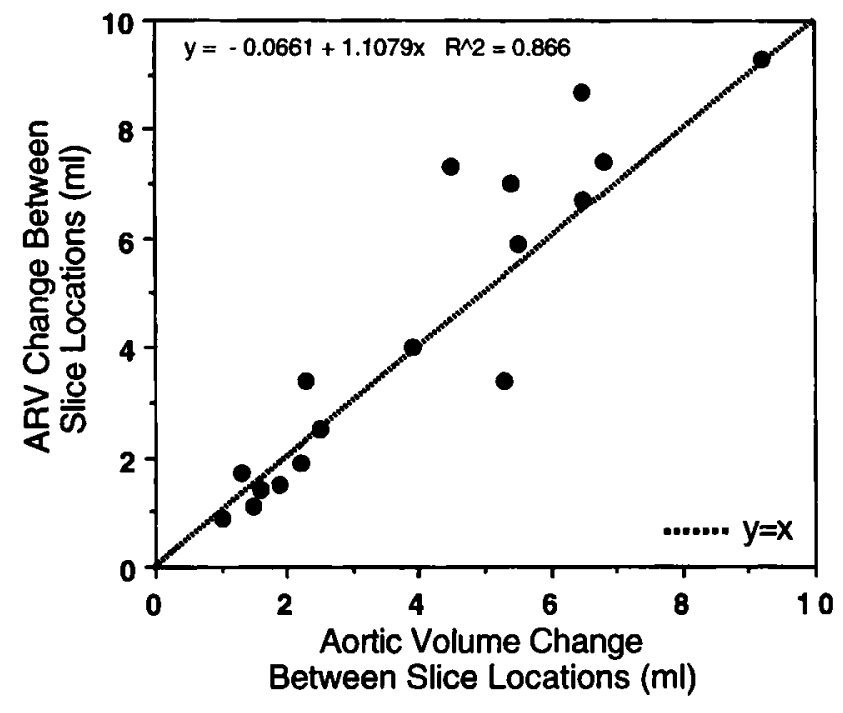

FIG. 6. Aortic volume change during the cardiac cycle (as measured directly from the images) between slice Locations 1 and 2 or 2 and 3 (see Fig. 1) versus ARV difference between these locations as measured with PVM. A range of aortic diameter changes (between 10 and $50 \%$ ) was used during the experiments resulting in a range of aortic volume changes.

two locations. A good correlation was observed (Fig. 6), indicating the importance of compliance.

Similar to the in vitro results, the preliminary in vivo measurements showed a decrease in the measured ARV with distance from the valve due to compliance. The accuracy of the in vivo measurements cannot be validated, due to the lack of any other reliable quantitative clinical method. However, the agreement in the tendency between in vitro and in vivo data is a strong indication of the importance of the in vitro results and suggests that, to

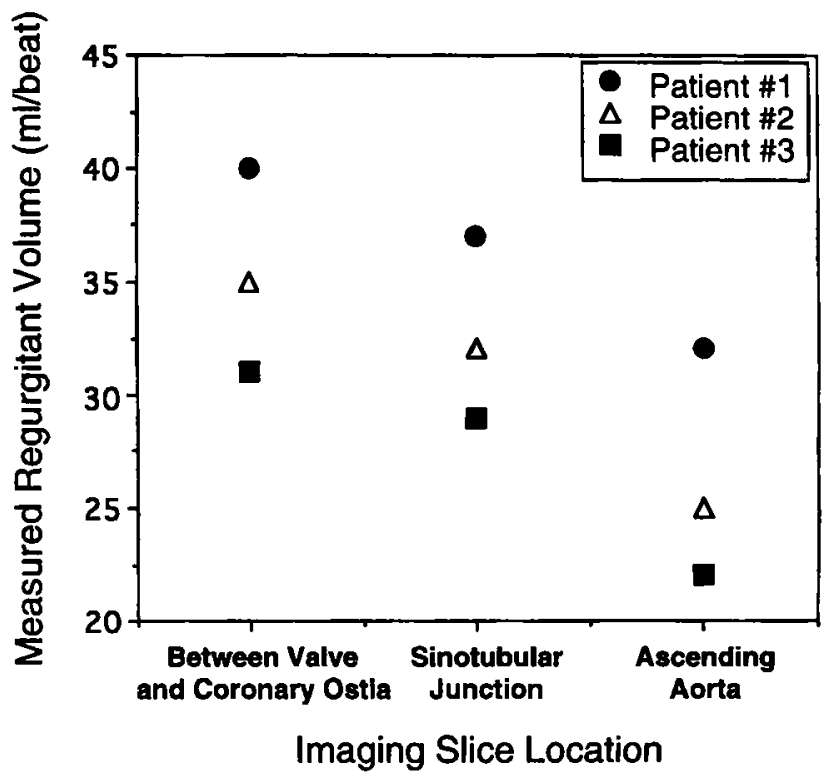

FIG. 7. Measured regurgitant volume on three patients with moderate-to-severe AR: Note the decrease in ARV as the slice location is moved away from the valve annulus. 
avoid errors, the proper slice location is between the valve annulus and the coronary ostia.

By moving the slice close to the regurgitant orifice, of consideration was the effect of flow field in that region. Generally, large convective acceleration can lead to considerable velocity errors (26) and misregistrations of the exact location of measurement $(26,27)$ when using PVM. Nevertheless, the present results between the valve and the coronary ostia are accurate. One should note that the measurements were not taken too close to the valvular level (where the slice would be in a region of too rapid acceleration). Therefore, the results should not be significantly affected since, in addition, short TEs (6-9 ms in this study) were used. Use of short TEs prevents dephasing of the MR signal in regions of accelerating and, generally, complex flow and allow reliable measurements of blood velocity. In the present study, with the help of the LVOT cine set of images, the measurements between the valve annulus and the coronary ostia were taken so that the $5-\mathrm{mm}$ thick slice would be as far as possible from the regurgitant orifice, regardless of any aortic motion in the in vivo cases. Although, some acceleration of flow was present (recognized by a hemispherically shaped reduced-signal area at the tip of the valve leaflets in the LVOT scout image during diastole, see Fig. 3b), the velocity information was not lost or significantly distorted.

Both in vitro and in vivo measurements at the valve level provided unreliable results. In addition, the quality of the images at the valvular level was unsatisfactory, making the analysis more unreliable. Use of extra-short $T E s \quad(<4 \mathrm{~ms})$ has been reported to partially reduce the problem of signal loss and signal phase distortion due to very large acceleration and turbulence $(28,29)$. However, the shorter the $T E$, the lower the signal-to-noise ratio due to hardware limitations, and this causes uncertainties and possible errors in the calculation of the flow rate through the orifice. In addition, partial volume effects and proper slice thickness selection are important factors in the accuracy of the regurgitant measurements. Generally, good quality images make the analysis more objective. The images from the in vivo measurements close to the valve were of good quality and can provide a reliable diagnosis.

This MR technique is based on the principle of mass conservation. Based on that principle, flow through the imaging slice will pass through the regurgitant orifice (since the effects of coronary flow and aortic compliance are eliminated if the imaging slice is placed close to the valve). The same principle is taken into account in the control volume concept, introduced in a previous study by Walker et al. (19), where, after acquiring a number of contiguous images in the region of a regurgitant orifice, and measuring all three velocity components, an imaginary cubical control volume encompassing the orifice was constructed to quantify the regurgitant flow. Although this approach is very promising for the quantification of mitral regurgitation, it is time consuming with conventional imaging techniques. Furthermore, the geometry of the aortic root could complicate its implementation in the case of AR. In addition, situations of perivalvular leakage can be reliably diagnosed by a single slice measurement, in contrast to the multislice control volume method. Another important advantage of the single slice technique, compared to other techniques for quantifying $A R$, is that it is not affected by the presence of regurgitation of the other heart valves (in contrast to the volumetric MRI). If one adds the simplicity and speed of the single slice technique (in the regular clinical situation, a total time of $20-30 \mathrm{~min}$ will be required for preparation, scanning and data analysis) to all advantages above, the conclusion drawn is that it seems the most reliable and convenient noninvasive quantitative approach for AR diagnosis.

On the other hand, all sources of error common in all MRI procedures (blood motion, cardiac motion, respiratory motion, cardiac arrhythmia, and patient motion) could introduce errors in the implementation of this technique and they have to be thoroughly investigated. From the in vivo part of this study, it was observed that aortic motion did not affect the reliability of position of the slice between the valve and the coronary ostia, mainly because such a motion does not happen exclusively in the through-slice (through-plane) direction [as seen in this study and based on other reports $(30,31)]$. Also, since in diastole cardiac motion is not too rapid (30), a relatively high temporal resolution of the cine PVM acquisition (as in the present study) will take into account, as much as possible, the in-plane motion. Nevertheless, the in vivo observations from the present work can only be indicative about the effects of cardiac and respiratory motion. Stronger conclusions about these effects could be drawn from a large amount of clinical data from which more information could be obtained for additional improvement of this approach.

\section{CONCLUSION}

In this study, the first important step toward establishing magnetic resonance phase velocity mapping in quantifying aortic regurgitation was taken, by showing that the regurgitant flow rate can be accurately measured by using a single slice between the aortic valve and the coronary ostia level with conventional imaging techniques. Away from the valve, aortic compliance and coronary flow introduce considerable errors in the ARV measurements. The technique is not significantly affected by the presence of acceleration close to the regurgitant orifice. The agreement in the tendency between in vitro and in vivo results indicates the great potential of the technique clinically.

\section{REFERENCES}

1. C. H. Croft, K. Lipscomb, K. Mathis, B. G. Firth, P. Nicod, G. Tilton, M. D. Winnford, L. D. Hillis. Limitations of qualitative angiographic grading in aortic or mitral regurgitation. Am. J. Cardiol. 53, 1593 1598 (1984)

2. M. Ciobanu, A. S. Abbasi, M. Allen, A. Hermer, R. Spellberg, Pulsed Doppler echocardiography in the diagnosis of severity of aortic regurgitation. Am. J. Cardiol. 49, $339-343$ (1982).

3. C. Veyrat, A. Ameur, C. Gourtchiglouian, A. Lessana, G. Abitbol, D. Kalmanson, Calculation of pulsed Doppler left ventricular outflow tract regurgitant index for grading the severity of aortic regurgitation. Am. Heart I. 108, 507-515 (1984).

4. B. A. J. Angelsen, S. A. Slordahl, J. E. Solbakken, S. O. Samstad, D. T. Linker, H. Torp, H. Piene, Estimation of regurgitant volume and 
orifice in aortic regurgitation combining CW Doppler and parameter estimation in a Windkessel-like model, IEEE Trans. Biomed. Eng. 37, 930-936 (1990).

5. S. Holm, P. Eriksson, K. Karp. G. Osterman, D. Teien, Quantitative assessment of aortic regurgitation by combined two-dimensional, continuous-wave and colour flow Doppler measurements. J. Int. Med. 231, 115-121 (1992).

6. G. J. Perry, F. Helmcke, N. C. Nanda, C. Byard, B. Soto, Evaluation of aortic insufficiency by Doppler color flow mapping. J. Am. Coll. Cardiol. 9, 952-959 (1987).

7. S. Wagner, W. Auffermann, P. Buser, T. H. Lim. B. Kircher, P. Pflugfelder. C. B. Higgins, Diagnostic accuracy and estimation of the severity of valvular regurgitation from the signal void on cine magnetic resonance images. Am. Heart /. 118, 760-767 (1989).

8. J--I. Suzuki, G. R. Caputo, C. Kondo, C. B. Higgins, Cine MR imaging of valvular heart disease: display and imaging parameters affect the size of the signal void caused by valvular regurgitation. AJR $\mathbf{1 5 5}$, 723-727 (1990).

9. A. L. Taylor, E. J. Eichhorn, M. E. Brickner, R. C. Eberhart, P. A. Grayburn, Aortic valve morphology: an important in vitro determinant of the proximal regurgitant jet width by Doppler color flow mapping. J. Am. Coll. Cardiol. 16, 405-412 (1990).

10. T. Reynolds, J. Abate, A. Tenney, M. G. Warner, The JH/LVOH method in the quantification of aortic regurgitation; how the cardiac sonographer may avoid an important potential pitfall. J. Am. Soc. Echocardiogr. 4, 105-108 (1991).

11. S. Globits, H. Mayr, A. Neuhold, D. Globar, Quantitative assessment of aortic regurgitation by magnetic resonance imaging. Eur. Heart $J$. 13, 78-83 (1992).

12. U. Sechtem, P. W. Pflugfelder, M. M. Cassidy, R. D. White, M. D. Cheitlin, N. B. Schiller, C. B. Higgins, Mitral or aortic regurgitation: quantification of regurgitant volumes with cine MR imaging. Radiology 167, 425-430 (1988).

13. M.-C. Dulce, G. H. Mostbeck, M. O'Sullivan, M. Cheitlin, G. R. Caputo, C. B. Higgins, Severity of aortic regurgitation: interstudy reproducibility of measurements with velocity-encoded cine MR imaging. Radiology 185, 234-240 (1992).

14. F. Recusani, G. S. Bargiggia, A. P. Yoganathan, A. Raisaro, L. M. Valdes-Cruz, H.-W. Sung, C. Bertucci, M. Gallati, V. A. Moises. I. A. Simpson, L. Tronconi, D. J. Sahn, A new method for quantification of regurgitant flow rate using color Doppler flow imaging of the flow convergence region proximal to a discrete orifice. Circulation 83, $594-604$ (1991).

15. E. G. Cape, J. D. Thomas, A. E. Weyman, A. P. Yoganathan, R. A. Levine, Threc-dimensional surface geometry correction is required for calculating flow by the proximal isovelocity surface area technique. J. Am. Soc. Echocardiogr. 8, 585-594 (1995).

16. M. Pu. P. M. Vandervoort, J. M. Rivera, J. D. Thomas, Proximal flow constraint by ventricular wall causes overestimation of regurgitant flow in mitral regurgitation: In vitro assessment. Circulation 88, I-110 (1993).

17. D. Meier, S. Maier, P. Beesiger, Quantitative flow measurements on phantoms and on blood vessels with MR. Magn. Reson. Med. 8, 25-34 (1988).

18. D. N. Firmin, G. L. Nayler, R. H. Klipstein, S. R. Underwood, R. S. O. Rees, D. B. Longmore, In vivo validation of MR velocity imaging. I. Comput. Assist. Tomogr. 11, 751-756 (1987).

19. P. G. Walker, S. Oyre, E. M. Pedersen, K. Houlind, F. S. A. Guenet, A P. Yoganathan. A new control volume method for calculating valvular regurgitation. Circulation 92, 579-586 (1995).

20. G. B. Cranney, C. S. Lotan, G. M. Pohost, Evaluation of aortic regurgitation by magnetic resonance imaging. Curr. Probl. Cardiol. 15, 87-114 (1990).

21. N. Honda, K. Machida, M. Hashimoto, T. Mamiya, T. Takahashi, T. Kamano, A. Kashimada, Y. Inoue, S. Tanaka, N. Yoshimoto, H. Matsuo, Aortic regurgitation: Quantitation with MR imaging velocity mapping. Radiology 186, 189-194 (1993).

22. L. Søndergaard, K. Lindvig, P. Hildebrandt, C. Thompsen, F. Stahlberg. T. Joen, $O$. Henriksen, Quantification of aortic regurgitation by magnetic resonance velocity mapping. Am. Heart J. 125, 1080-1090 (1993).

23. A. R. Snider, M. A. Enderlein, D. F. Teitel, R. P. Juster, Two-dimensional echocardiographic determination of aortic and pulmonary artery sizes from infancy to adulthood in normal subjects. Am. J. Cardiol. 53, 218-224 (1984).

24. R. G. Carlson, C. W. Lillihei, J. E. Edwards, Cystic medial necrosis of the ascending aorta in relation to age and hypertension. Am. J. Cardiol. 25, 411-415 (1970).

25. P. G. Walker, G. B. Cranney, M. B. Scheidegger, G. Waseleski, G. M. Pohost, A. P. Yoganathan, Semiautomated method for noise reduction and background phase error correction in MR phase velocity data. J. Magn. Reson. Imaging 3, 521-530 (1993).

26. J. N. Oshinski, D. N. Ku, D. E. Bohning, R. I. Pettigrew, Effects of acceleration on the accuracy of MR phase velocity measurements. J. Magn. Reson. Imaging 2, 665-670 (1992).

27. M. Kouwenhoven. M. B. M. Hofman. M. Sprenger, Motion induced phase shifts in MR: acceleration effects in quantitative flow measurements - a reconsideration. Magn. Reson. Med. 33, 766-777 (1995).

28. P. J. Kilner, D. N. Firmin, R. S. O. Rees, J. Martinez, D. J. Pennell. R. H. Mohiaddin, S. R. Underwood, D. B. Longmore, Valve and great vessel stenosis: assessment with MR jet velocity mapping. Radiology 178, 229-235 (1991).

29. L. Søndergaard, P. Hildebrandt, K. Lindvig, C. Thompsen, F. Stahlberg, E. Kassis, O. Henriksen, Valve area and cardiac output in aortic stenosis: quantification by magnetic resonance velocity mapping. Am. Heart J. 127, 1156-1164 (1993).

30. Y. Wang, S. J. Riederer, R. L. Ehmon, Respiratory motion of the heart: kinematics and the implications for the spatial resolution in coronary imaging. Magn. Reson. Med. 33, 713-719 (1995).

31. M. B. M. Hofman, A. C. van Rossum, M. Sprenger, N. Westerhof, Assessment of flow in the right human coronary artery by magnetic resonance phase contrast velocity measurement: effects of cardiac and respiratory motion. Magn. Reson. Med. 35, 521-531 (1996). 